\title{
Annual Report of the Korean Association of External Quality Assessment Service on General Chemistry (2018)
}

Yong-Wha Lee

Department of Laboratory

Medicine and Genetics,

Soonchunhyang University

Bucheon Hospital,

Soonchunhyang University

College of Medicine,

Bucheon, Korea

\section{Corresponding author:} Yong-Wha Lee

Department of Laboratory

Medicine and Genetics,

Soonchunhyang University

Bucheon Hospital,

Soonchunhyang University

College of Medicine, 170 Jomaru-

ro, Wonmi-gu, Bucheon 14584,

Korea

Tel: +82-32-621-5943

Fax: +82-32-621-5944

E-mail: lywmd@schmc.ac.kr

pISSN: 2384-2458

elSSN: 2288-7261
In 2018, the general chemistry proficiency testing program of the Korean Association of External Quality Assessment Service consisted of the routine chemistry and urine chemistry programs including 32 and 13 test items, respectively. The test method classification system was revised in the routine chemistry program, and a qualitative test of human chorionic gonadotropin was added in the urine chemistry program. The routine chemistry program was conducted 4 times a year, while the urine chemistry program was conducted twice a year. Statistical analysis data for the test method and reagent companies were reported based on the information and results of the test items provided by each institution. Statistics included the number of participating institutes, mean, standard deviation, coefficient of variation (CV), median, and minimum and maximum values for each group. Each report included tables, histograms, Levey-Jennings charts, and the standard deviation index showing the statistics of each test item. In the routine chemistry program, more than 1,000 institutions performed the 17 test items, and the number is continuously increasing. CV for each test item showed a tendency to increase with decreasing concentration of the proficiency material but was within $10 \%$ in most cases. Alkaline phosphatase and lactate dehydrogenase were found to have relatively high CVs because of the differences in results among test methods. In the urine chemistry program, albumin and protein showed high CVs, and the distribution of the test method was different from that of the routine chemistry program.

(J Lab Med Qual Assur 2019;41:51-64)

Key Words: Proficiency testing, General chemistry, Korean Association of External Quality Assessment Service

\section{서론}

대한임상검사정도관리협회에서는 2016년부터 새로운 운 영방식의 차세대 신빙도조사사업을 시행하고 있다. 2018년에 는 6 개 대분류하에 64 개 프로그램 단위별 운영체계로 확대되 어 프로그램별 검사종목도 319항목으로 증가하였다[1-3]. 임 상화학 분야는 6 개의 대분류 중 하나로서 일반화학검사 등 10 개의 중분류 분야로 구성되고 이들은 일반화학검사와 요화학 검사 등 24 개의 세부 프로그램으로 나뉜다. 일반화학검사 프 로그램에는 총 32 종의 검사항목이 포함되어 있고, 요화학검사 프로그램에는 요 human chorionic gonadotropin (hCG) 정 성검사가 추가되어 총 13 종의 검사항목이 포함되었다. 일반화
학검사 프로그램에 대해서는 검사항목별로 새로운 검사방법 분류체계를 적용하여 각각의 시약들에 대해 새로운 검사방법 명칭을 부여하였다.

저자들은 2018년 대한임상검사정도관리협회의 신빙도조사 사업으로 실시되었던 일반화학검사와 요화학검사에 대한 신 빙도조사사업 결과를 분석하여 보고하고자 한다.

\section{재료 및 방법}

\section{1. 대상}

일반화학검사 프로그램은 연 4회에 걸쳐 회차별로 3 개의 정 도관리물질이 이용되어 시행되었다. 물질은 냉장상태가 유지 


\section{Journal of LABORATORY MEDICINE and QUALITY ASSURANCE}

\section{Yong-Wha Lee • External Quality Assessment of General Chemistry}

될 수 있도록 아이스팩이 내장된 특수 제작박스에 넣어 참여 등록기관을 대상으로 각 회차별로 2월, 4월, 8월과 10월에 발 송되었다. 요화학검사 프로그램은 연 2회에 걸쳐, 회차 별로 3 개의 정도관리 물질이 이용되었고 1회차와 2회차를 각각 3월 과 9월에 발송하였다.

\section{2. 정도관리물질과 검사항목}

일반화학검사의 정도관리물질은 사람 혈청을 기질로 한 분 말제품인 Randox사(Randox Testing Services, London, UK)와 Bio-Rad사(Bio-Rad Laboratories, Hercules, CA, $\mathrm{USA}$ )의 사람 혈청을 기질로 한 분말제품을 사용하였다 (Table 1). 검사항목은 성인과 소아의 추정 사구체여과율 항목 을 포함하여 총 32 항목이었다. 요화학검사의 정도관리물질은 Bio-Rad사의 Lyphochek Quantitative Urine Control (BioRad Laboratories)을 사용하였다(Table 2). 사전에 공지된 일 정에 따라 물질을 수령한 참여기관에서는 검사 시행 후 지정된
회신 마감일 이내에 대한임상검사정도관리협회 신빙도조사사 업 홈페이지(http://eqas.keqas.org)에 결과를 입력하도록 하 였다. 기기회사와 시약회사로부터 제공된 검사항목별 검사방 법, 기기와 시약에 대해 기초자료를 검토한 바를 토대로 참여 기관이 홈페이지상에서 해당 검사항목에 대한 검사정보 선택 과 결과 입력이 가능하도록 전산체계를 구축하였다. 결과 입력 기간 내에 최종 전송을 했더라도 결과 수정이 가능하도록 하였 다.

\section{3. 검사법 신분류체계 적용}

일반화학검사 프로그램의 검사항목별 검사방법 분류체계의 현황과 기기시약별 지정된 검사방법과 동료집단 설정상의 개 선점을 분석하였고, 일반화학검사 관련 국내·외 주요 관련 자 료와 문헌 및 검사기기와 시약업체로부터 제공되는 설명서를 검토함으로써 참가기관에서 제공하는 검사방법에 대한 정보 및 신빙도조사 결과에 대해서 정확한 동료집단 분류 및 통계분

Table 1. Control materials analyzed and released dates from the trials of general chemistry in 2018

\begin{tabular}{|c|c|c|c|c|c|}
\hline Trial & Material no. & Manufacturer & Product name & Lot no. & Released date \\
\hline \multirow[t]{3}{*}{1 st } & CC-18-01 & Randox & Human low serum $5 \mathrm{~mL}$ & 273ULCM & 26 February \\
\hline & CC-18-02 & Randox & Human normal serum $5 \mathrm{~mL}$ & 1250UNCM & \\
\hline & CC-18-03 & Randox & Human elevated serum $5 \mathrm{~mL}$ & 973UECM & \\
\hline \multirow[t]{3}{*}{ 2nd } & CC-18-04 & Randox & Human low serum $5 \mathrm{~mL}$ & 274ULCM & 23 April \\
\hline & CC-18-05 & Randox & Human normal serum $5 \mathrm{~mL}$ & 1251UNCM & \\
\hline & CC-18-06 & Randox & Human elevated serum $5 \mathrm{~mL}$ & 974UECM & \\
\hline \multirow[t]{3}{*}{$3 \mathrm{rd}$} & CC-18-07 & Bio-Rad & Lyphochek assayed \& unassayed chemistry control & 26441 & 20 August \\
\hline & CC- $18-08$ & Bio-Rad & Lyphochek assayed \& unassayed chemistry control & 26442 & \\
\hline & CC-18-09 & Bio-Rad & Lyphochek assayed \& unassayed chemistry control & 26432 & \\
\hline \multirow[t]{3}{*}{4 th } & CC-18-10 & Bio-Rad & Lyphochek assayed \& unassayed chemistry control & 28831 & 1 October \\
\hline & CC-18-11 & Bio-Rad & Lyphochek assayed \& unassayed chemistry control & 28832 & \\
\hline & CC-18-12 & Bio-Rad & Lyphochek assayed \& unassayed chemistry control & 26452 & \\
\hline
\end{tabular}

The instruments were from the following companies: Randox Laboratories (London, UK) and Bio-Rad Laboratories (Hercules, CA, USA).

Table 2. Control materials analyzed and released dates from the trials of urine chemistry in 2018

\begin{tabular}{llclll}
\hline Trial & Material no. & Manufacturer & Product name & Lot no. & Released date \\
\hline \multirow{2}{*}{ 1st } & CUC-18-01 & Bio-Rad & Lyphochek quantitative urine control & 63381 & 63382 \\
& CUC-18-02 & Bio-Rad & Lyphochek quantitative urine control & 633 \\
\multirow{2}{*}{ 2nd } & CUC-18-03 & Bio-Rad & Lyphochek quantitative urine control & 63383 \\
& CUC-18-04 & Bio-Rad & Lyphochek quantitative urine control & 63421 & 63422 \\
& CUC-18-05 & Bio-Rad & Lyphochek quantitative urine control & 63411 \\
\hline
\end{tabular}

The instruments were from the following company: Bio-Rad Laboratories (Hercules, CA, USA). 


\section{Journal of LABORATORY MEDICINE and QUALITY ASSURANCE}

\section{Yong-Wha Lee • External Quality Assessment of General Chemistry}

석의 기초가 될 수 있는 새로운 검사방법 명칭과 분류체계를 정립하여 일반화학검사 프로그램에 적용하였다.

Table 3. Number of laboratories that participated in each test of general chemistry in 2018

\begin{tabular}{|c|c|c|c|c|}
\hline \multirow{2}{*}{ Test } & \multicolumn{4}{|c|}{ Trials } \\
\hline & 1st & 2nd & 3rd & 4th \\
\hline Alanine aminotransferase & 1,568 & 1,639 & 1,676 & 1,660 \\
\hline Albumin & 1,443 & 1,512 & 1,548 & 1,534 \\
\hline Alkaline phosphatase & 1,385 & 1,451 & 1,479 & 1,467 \\
\hline Amylase & 800 & 825 & 820 & 814 \\
\hline Aspartate aminotransferase & 1,567 & 1,638 & 1,675 & 1,659 \\
\hline Bilirubin, direct & 782 & 813 & 813 & 809 \\
\hline Bilirubin, total & 1,456 & 1,521 & 1,557 & 1,543 \\
\hline Calcium & 698 & 724 & 736 & 734 \\
\hline Chloride & 991 & 1,034 & 1,051 & 1,046 \\
\hline Cholesterol, total & 1,557 & 1,626 & 1,662 & 1,646 \\
\hline Creatine kinase & 652 & 667 & 676 & 673 \\
\hline Creatinine & 1,520 & 1,595 & 1,640 & 1,628 \\
\hline $\begin{array}{l}\text { Gamma-glutamyl } \\
\text { transpeptidase }\end{array}$ & 1,520 & 1,588 & 1,622 & 1,608 \\
\hline Glucose & 1,543 & 1,614 & 1,651 & 1,635 \\
\hline $\begin{array}{l}\text { High density lipoprotein } \\
\text { cholesterol }\end{array}$ & 1,443 & 1,501 & 1,533 & 1,519 \\
\hline Iron & 403 & 416 & 421 & 419 \\
\hline Lactate dehydrogenase & 871 & 899 & 916 & 909 \\
\hline Lipase & 392 & 399 & 408 & 403 \\
\hline $\begin{array}{l}\text { Low density lipoprotein } \\
\text { cholesterol }\end{array}$ & 880 & 911 & 920 & 916 \\
\hline Magnesium & 280 & 283 & 290 & 290 \\
\hline Osmolality & 146 & 151 & 151 & 149 \\
\hline Phosphorus & 649 & 676 & 693 & 687 \\
\hline Potassium & 1,004 & 1,048 & 1,064 & 1,060 \\
\hline Protein, total & 1,429 & 1,494 & 1,529 & 1,516 \\
\hline Sodium & 1,004 & 1,048 & 1,064 & 1,060 \\
\hline Total $\mathrm{CO}_{2}$ & 201 & 209 & 216 & 214 \\
\hline Total iron-binding capacity & 367 & 376 & 382 & 381 \\
\hline Triglyceride & 1,515 & 1,587 & 1,617 & 1,601 \\
\hline Urea nitrogen & 1,499 & 1,570 & 1,602 & 1,591 \\
\hline Uric acid & 1,185 & 1,242 & 1,262 & 1,254 \\
\hline $\begin{array}{l}\text { Estimated glomerular } \\
\text { filtration rate, adult }\end{array}$ & 279 & 287 & 295 & 293 \\
\hline $\begin{array}{l}\text { Estimated glomerular } \\
\text { filtration rate, child }\end{array}$ & 180 & 184 & 189 & 193 \\
\hline
\end{tabular}

\section{4. 결과 판정 및 분석}

일반화학검사와 요화학검사 각각에 대해서 각 기관에서 입 력한 각 검사항목에 대한 정보와 결과를 기반으로 검사방법, 기기, 시약에 따라 통계분석을 시행하였고 이를 전체 참여기관 의 특성을 보여주는 공통보고서와 개별기관의 평가자료를 보 여주는 기관별 보고서로 나누어 보고하였다. 공통보고서는 3 단계로 그룹화하여 통계치를 제시하였다. 전체 참여기관에 해 당하는 통계, 검사방법을 기준분류로 한 그룹의 통계와 검사방 법별로 시약회사를 세 분류한 그룹의 통계를 각각 제시하였다.

제시된 통계에는 각 그룹별 참여기관 수, 평균, 표준편차, 변 동계수, 중앙값, 최소값과 최대값이 포함되도록 하였고 참여 기관 수, 중앙값, 최소값과 최대값은 이상치를 제거하지 않은 수치를 제시하였고 평균, 표준편차와 변동계수는 각 그룹별 로 이상치를 제거한 후 산출된 수치를 사용하였다. 또한 해당 분류에서 이상치를 제거한 후 기관 수가 8개 미만인 경우 평 균, 표준편차와 변동계수를 제시하지 않았고 기관 수가 3 개 미 만인 경우 중앙값도 제시하지 않았다. 이상치는 각 해당 분류 에서 75퍼센타일 값(Q3)과 25퍼센타일 값(Q1)의 차(Q3-Q1, interquartile range $[\mathrm{IQR}])$ 의 1.5배를 초과하여 Q1보다 낮 거나 Q3보다 높은 결과값 $(<\mathrm{Q} 1-1.5 \times \mathrm{IQR}$ 또는 $>\mathrm{Q} 3+1.5 \times$ $\mathrm{IQR}$ )으로 설정하였다.

개별보고서는 각 검사항목별로 통계치를 보여주는 표, 히 스토그램과 레비-제닝스 차트로 구성되도록 하였다. 통계치 를 제시한 표에는 각 기관의 결과값과 각 분류별 통계치를 제

Table 4. Number of laboratories that participated in each test of urine chemistry in 2018

\begin{tabular}{lcc}
\hline \multirow{2}{*}{ Test } & \multicolumn{2}{c}{ Trials } \\
\cline { 2 - 3 } & 1st & 2nd \\
\hline Albumin & 166 & 172 \\
Calcium & 151 & 155 \\
Chloride & 177 & 183 \\
Creatinine & 206 & 209 \\
Glucose & 135 & 137 \\
Magnesium & 109 & 108 \\
Phosphorus & 138 & 139 \\
Potassium & 178 & 184 \\
Protein & 173 & 177 \\
Sodium & 180 & 186 \\
Urea nitrogen & 152 & 156 \\
Uric acid & 145 & 146 \\
Urine human chorionic gonadotropin & 210 & 215 \\
(qualitative) & & \\
\hline
\end{tabular}




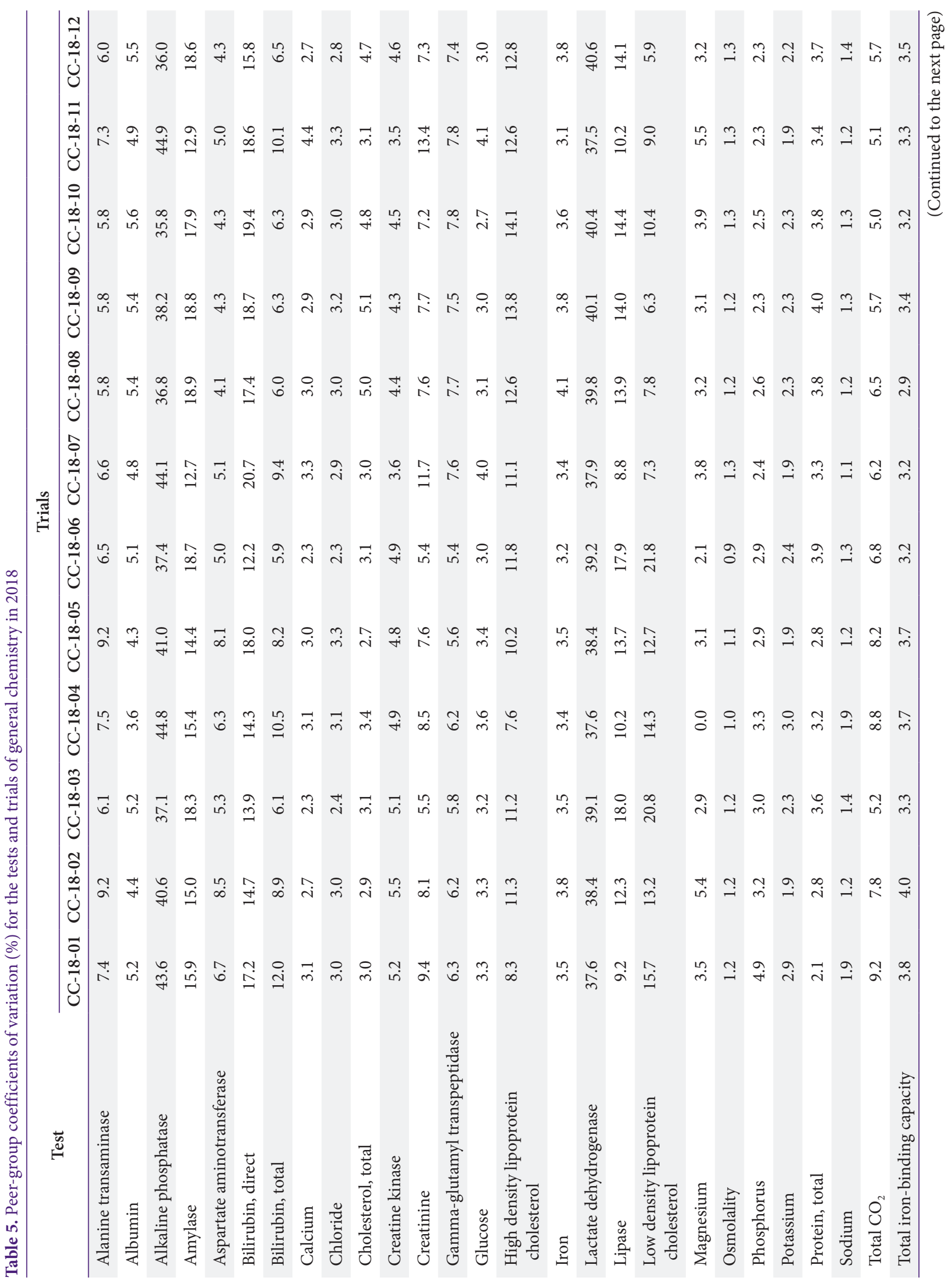


Journal of LABORATORY MEDICINE and QUALITY ASSURANCE

Yong-Wha Lee • External Quality Assessment of General Chemistry

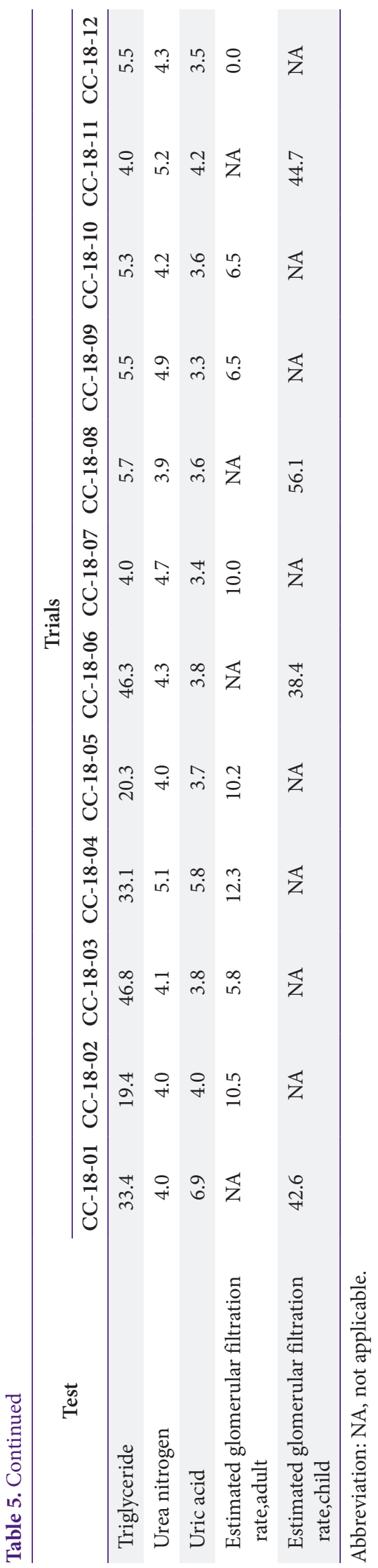

시하고 기준분류와 세분류에서는 표준편차지수(standard deviation index, SDI)를 함께 제시하였다. 전체 결과에 대해 서는 $\mathrm{SDI}$ 를 제시하지 않았고 각 그룹에서 이상치 제거 후 기 관 수가 8개 미만일 경우 SDI를 제시하지 않았다. 표준편차가 0 이지만 기관의 결과값이 평균과 다를 경우에도 $\mathrm{SDI}$ 를 제시하 지 않았다.

히스토그램에서는 전체 기관의 분포와 기준 분류별 분포를 제시하였고 각 기관의 위치를 표시하였다. 레비-제닝스 차트 는 기준 분류별 SDI를 이용하여 작성하였다.

\section{결과 및 고찰}

2018년 일반화학검사 프로그램의 특징으로 검사항목별로 새로운 검사방법 명칭과 분류체계를 적용하여 이를 기반으로 통계분석 및 결과를 보고한 점과 요화학검사 프로그램에 요 $\mathrm{hCG}$ 정성검사를 추가한 점을 들 수 있다. 기존 검사방법 분류 체계로서는 수용 안 되는 시약이 증가함에 따라 검사방법을 기 타 방법으로 선택하는 사례가 증가하였고, 일부 검사항목에 대 해서 현재에는 사용되지 않는 과거의 검사방법이 그대로 적용 되거나 제조사 명칭이 검사방법 명칭으로 사용된 사례가 있었 다. 검사방법 명칭과 관련된 국내·외 관련 자료를 수집하고 분석하여 검사항목별 신 분류안을 적용함으로써 정확한 동료 집단 설정과 데이터 오분류 및 누락 방지를 통해 신뢰할 수 있 는 신빙도조사 결과를 제공할 수 있게 되었다.

일반화학검사 프로그램에서는 1,000 개 이상의 기관이 참여

Table 6. Peer-group coefficients of variation (\%) for the tests and trials of urine chemistry in 2018

\begin{tabular}{lrrrrrr}
\hline \multirow{1}{*}{ Test } & \multicolumn{6}{c}{ Trials } \\
\cline { 2 - 7 } & CUC- & CUC- & CUC- & CUC- & CUC- & CUC- \\
& $\mathbf{1 8 - 0 1}$ & $\mathbf{1 8 - 0 2}$ & $\mathbf{1 8 - 0 3}$ & $\mathbf{1 8 - 0 4}$ & $\mathbf{1 8 - 0 5}$ & $\mathbf{1 8 - 0 6}$ \\
\hline Albumin & 30.0 & 19.0 & 19.4 & 14.2 & 20.3 & 32.5 \\
Calcium & 4.0 & 2.7 & 2.3 & 4.3 & 2.6 & 3.4 \\
Chloride & 8.8 & 2.5 & 2.5 & 9.0 & 2.4 & 8.7 \\
Creatinine & 5.5 & 4.9 & 4.8 & 5.2 & 4.9 & 5.1 \\
Glucose & 2.2 & 2.2 & 2.2 & 3.3 & 2.6 & 1.3 \\
Magnesium & 3.0 & 2.8 & 3.5 & 3.3 & 3.6 & 3.6 \\
Phosphorus & 2.5 & 2.6 & 2.9 & 2.6 & 2.8 & 2.8 \\
Potassium & 2.1 & 3.1 & 3.4 & 1.8 & 3.6 & 1.9 \\
Protein & 11.0 & 9.0 & 8.6 & 9.9 & 9.0 & 10.5 \\
Sodium & 2.8 & 1.2 & 1.1 & 2.2 & 1.1 & 2.3 \\
Urea nitrogen & 2.9 & 2.8 & 2.3 & 3.3 & 3.1 & 3.2 \\
Uric acid & 4.3 & 3.5 & 3.6 & 4.6 & 3.7 & 4.5 \\
\hline
\end{tabular}




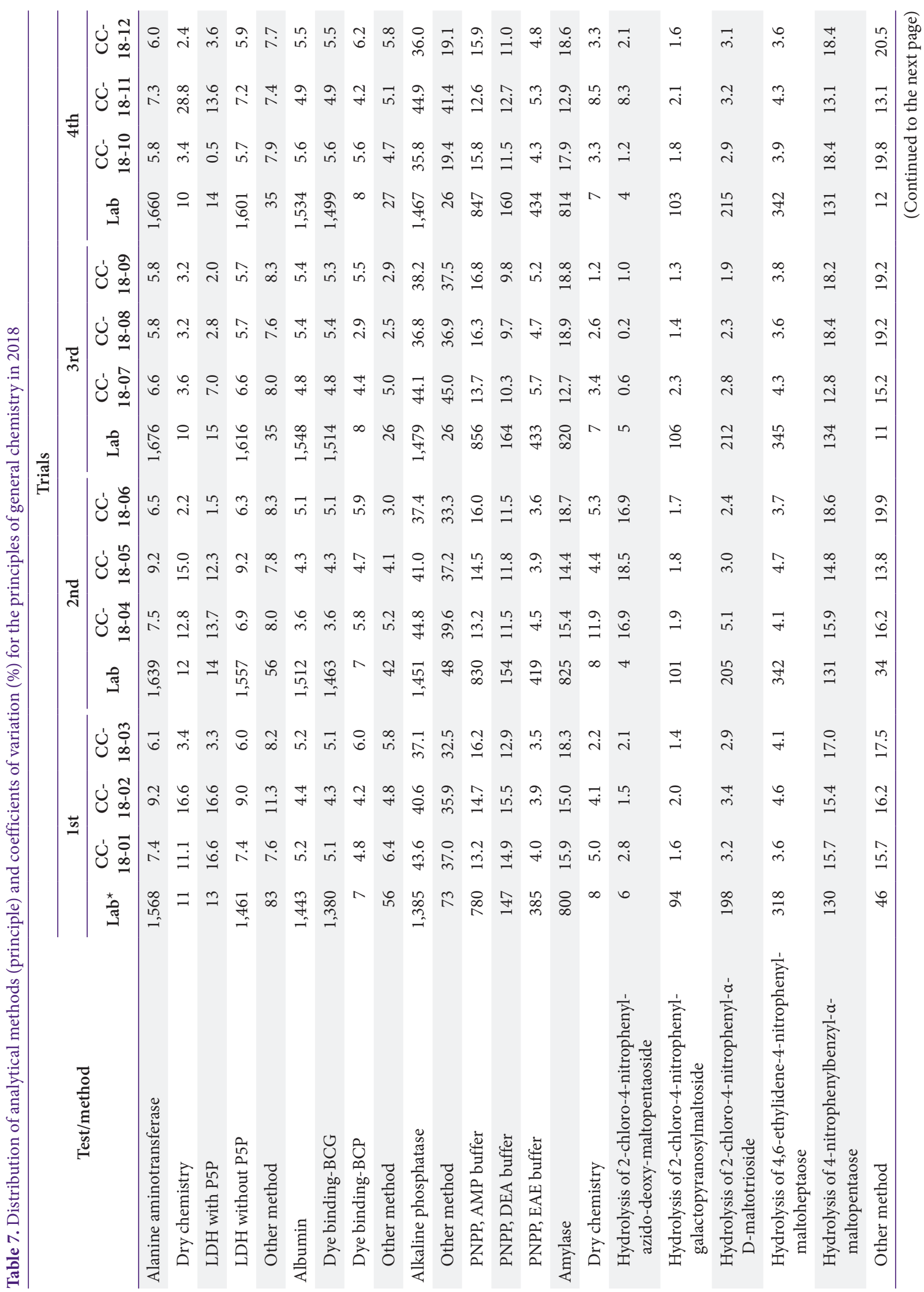




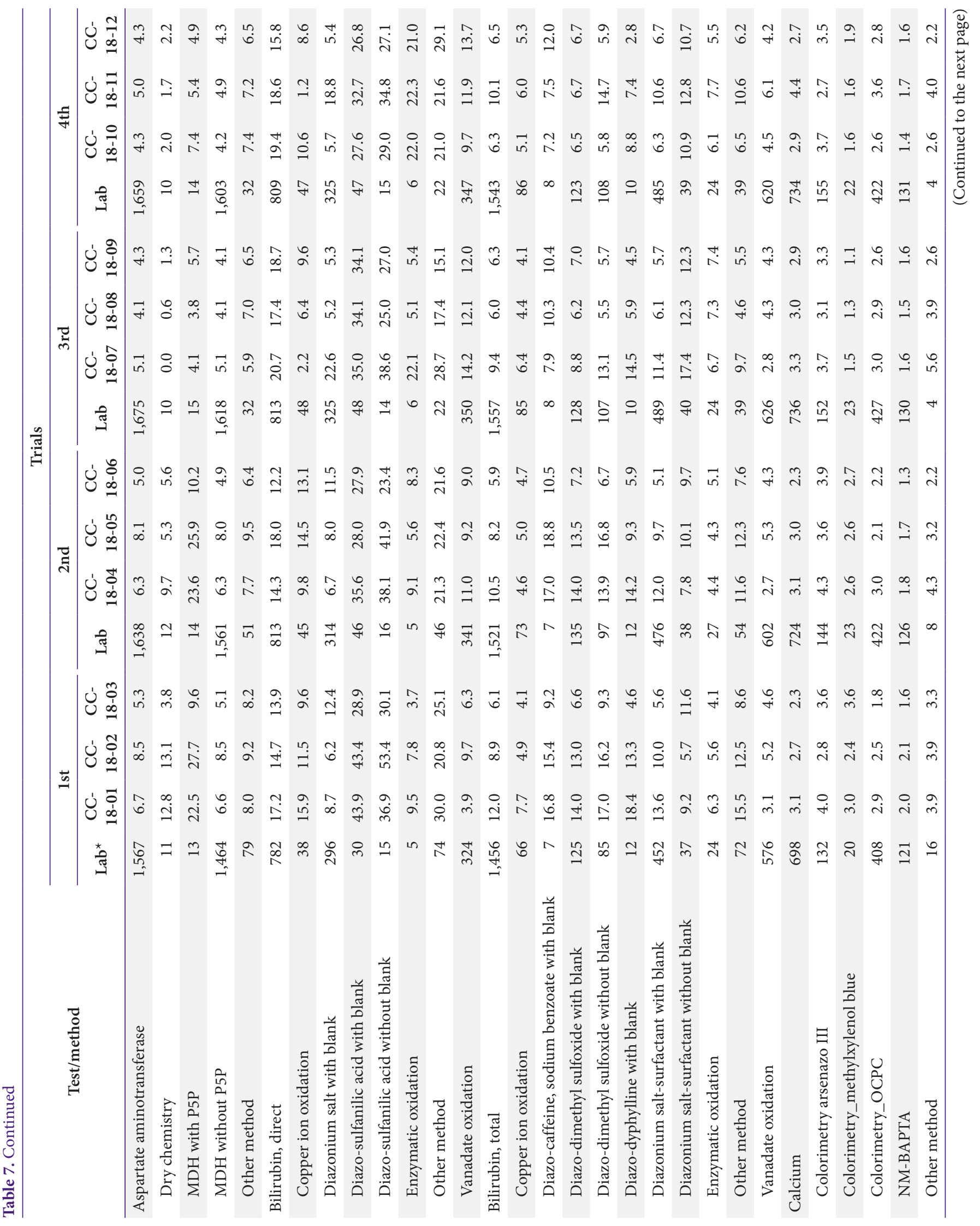




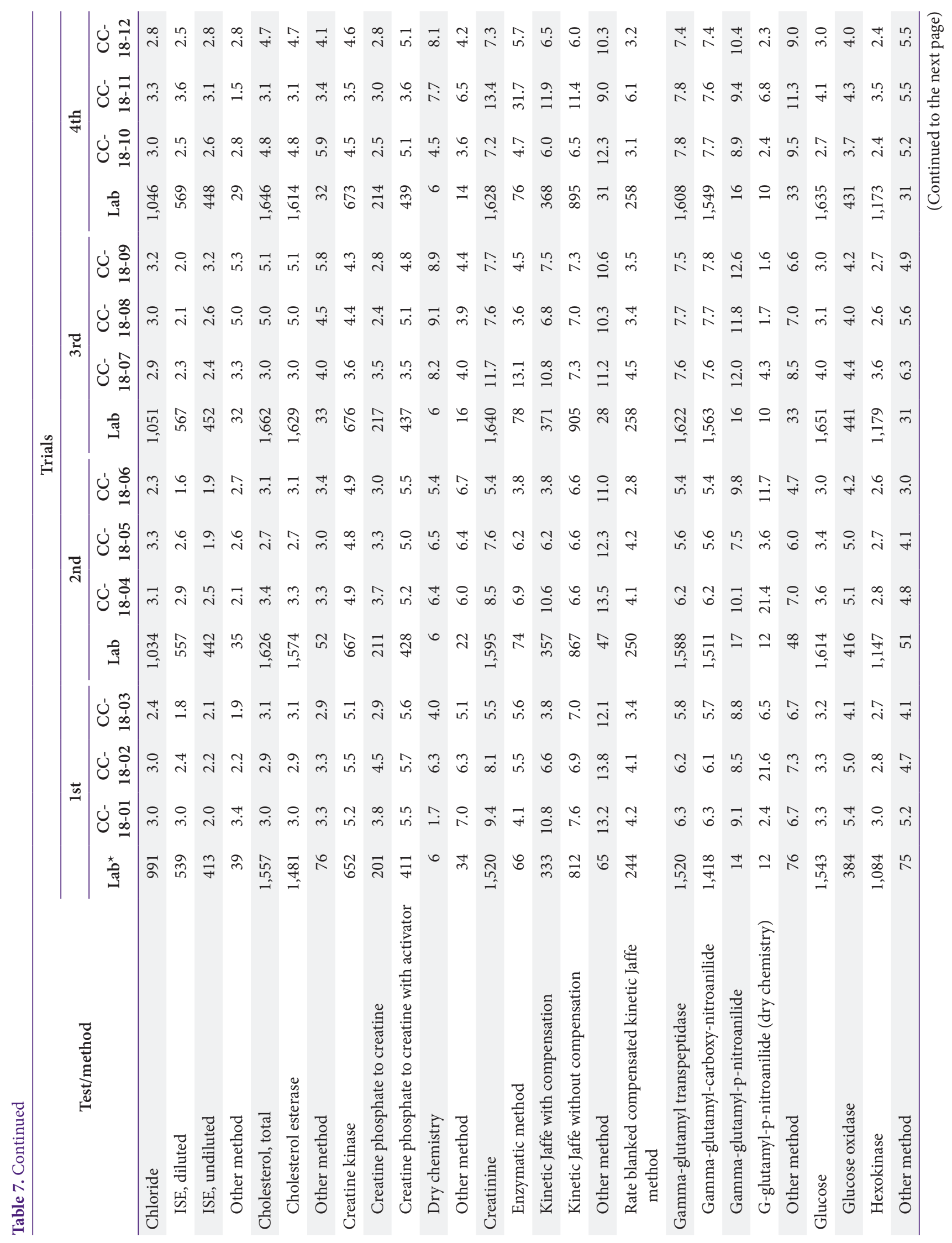




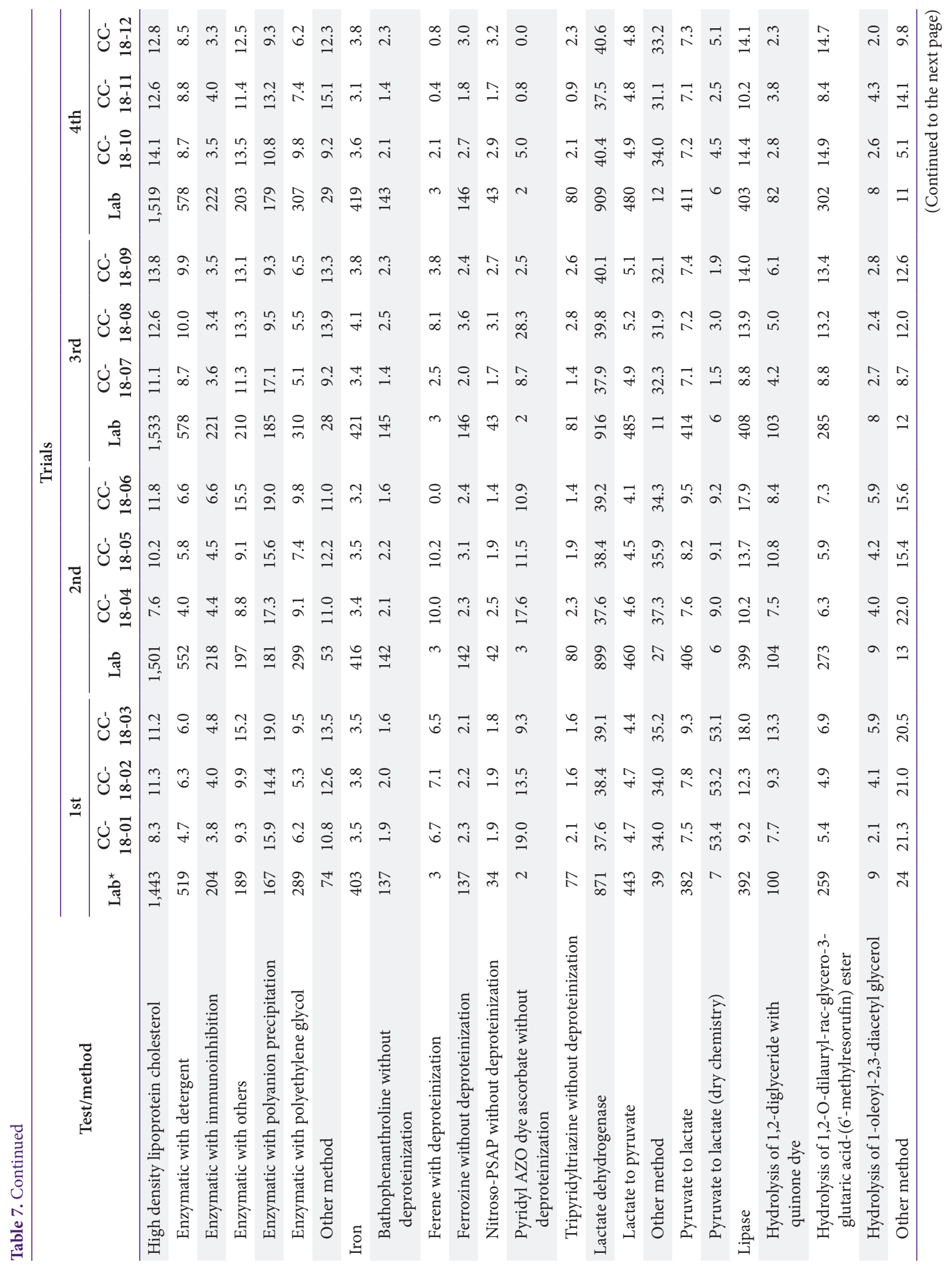




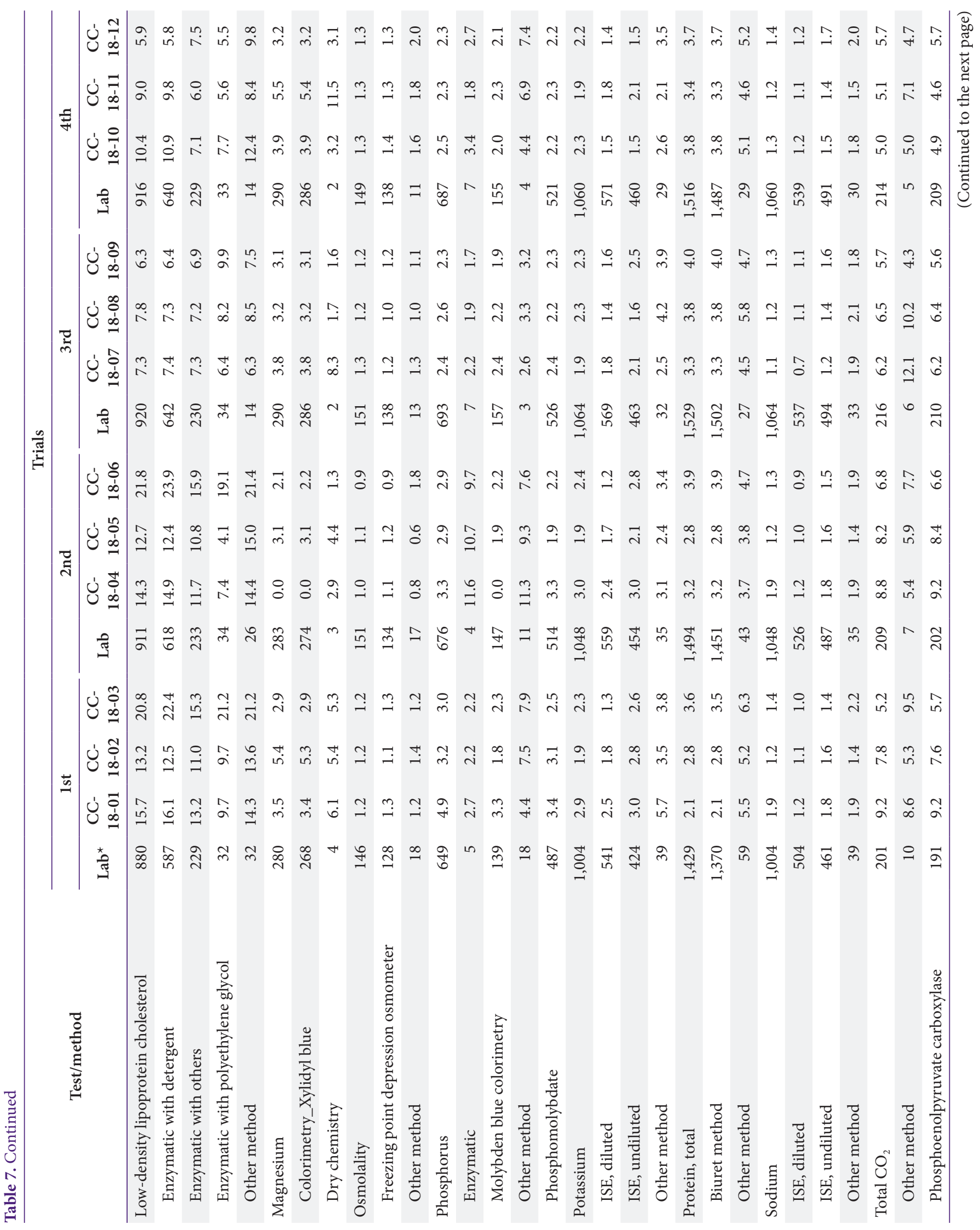




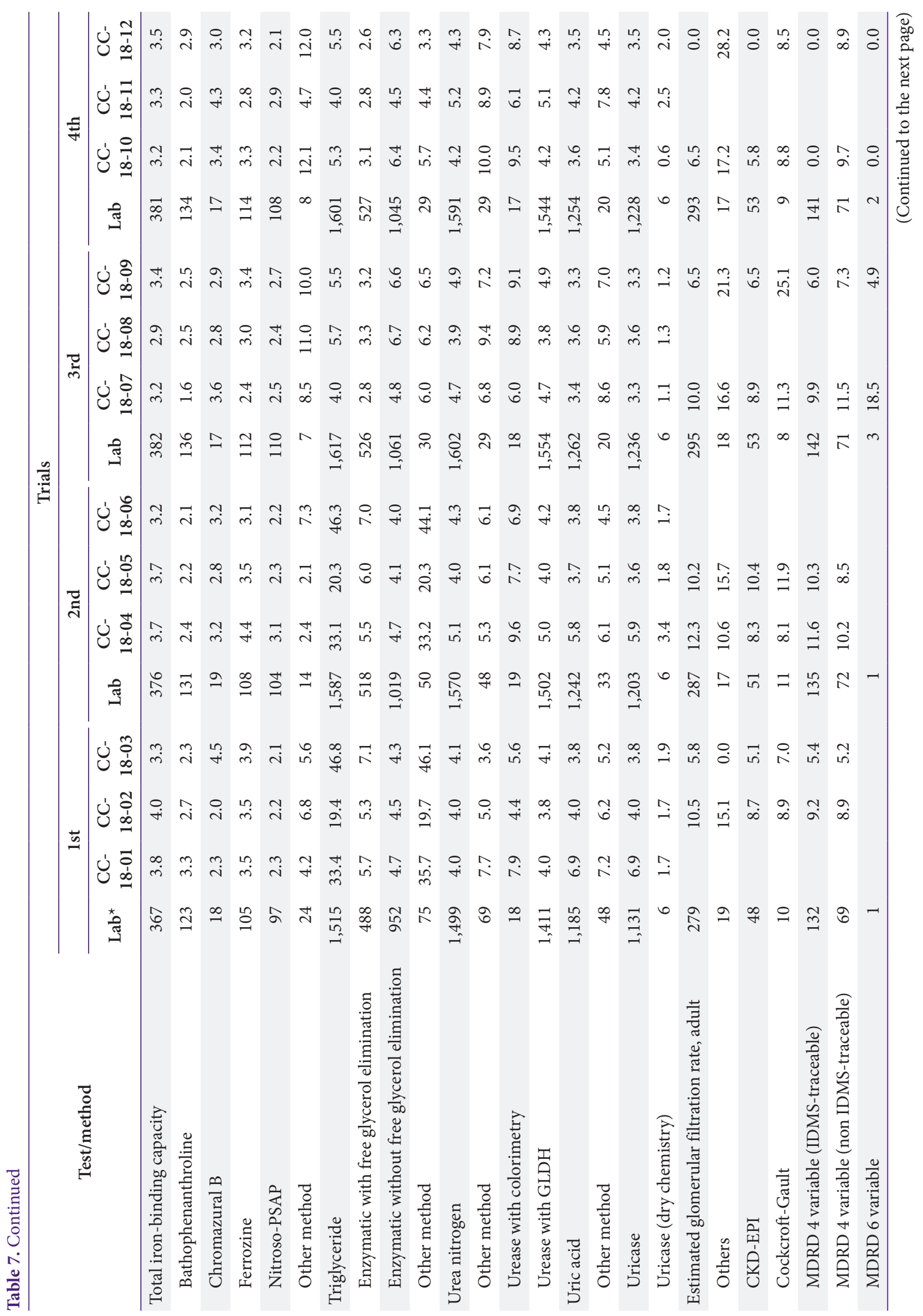




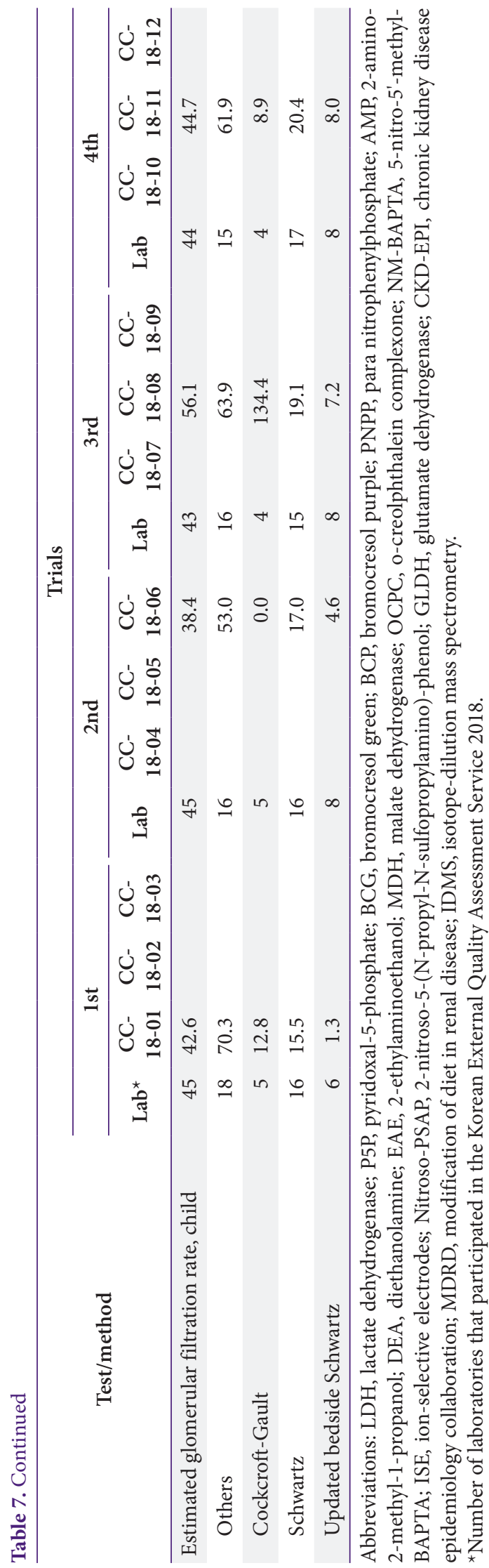

하는 검사항목은 alanine aminotransferase (ALT), albumin, alkaline phosphatase, aspartate aminotransferase (AST), total bilirubin, chloride, total cholesterol, creatinine, gamma-glutamyl transferase, glucose, high-density lipoprotein (HDL) cholesterol, potassium, total protein, sodium, triglyceride, urea nitrogen과 uric acid 등이었고 1 회차와 2회차에 비해 3 회차와 4 회차의 참가기관 수가 증가하 였다(Table 3). 요화학검사 프로그램에서는 새로 추가된 검 사항목인 요 $\mathrm{hCG}$ 정성검사에 참여하는 기관이 가장 많았고 creatinine검사가 뒤를 이었다(Table 4).

일반화학검사 프로그램에서 변동계수는 각 검사항목별 회 차별로 상대적으로 정도관리물질의 농도가 낮을수록 높은 경 향을 보였다(Table 5). 대부분 $10 \%$ 이내의 변동계수를 보 였지만 alkaline phosphatase, amylase, direct bilirubin, lactate dehydrogenase (LDH), lipase, HDL cholesterol, low-density lipoprotein cholesterol과 triglyceride 등의 일부 방법에서 $10 \%$ 이상의 높은 변동계수를 보였다. 물론 동일한 검사법을 사용하는 그룹 내에서는 비교적 작은 변동계수를 보 였으나 alkaline phosphatase와 $\mathrm{LDH}$ 는 검사법 간에 결과의 차이가 유의하게 큼으로써 변동계수도 상대적으로 큰 것으로 관찰되었다(Table 5). 요화학검사 프로그램에서 각 검사항목 별 변동계수는 대부분 $10 \%$ 이내의 값을 보였으나 albumin과 protein은 상대적으로 높은 변동계수를 보였다(Table 6). 변 동계수는 각각 기관의 상대적 위치를 나타내는 $\mathrm{SDI}$ 와도 관련 되므로 변동계수가 큰 경우 $\mathrm{SDI}$ 는 상대적으로 작아질 수 있으 므로 결과해석 시 고려되어야 한다.

일반화학검사에 있어서 한 가지 검사방법이 전체의 $80 \%$ 를 넘는 검사로는 albumin의 dye binding bromocresol green법, ALT의 LDH without pyridoxal-5-phosphate (P5P)법, AST 의 malate dehydrogenase without P5P법, total cholesterol 의 cholesterol esterase법, gamma-glutamyl transpeptidase 의 gamma-glutamyl-carboxy-nitroanilide법, magnesium 의 colorimetry-xylidyl blue법, osmolality의 freezing point depression osmometer법, total protein의 biuret법, total $\mathrm{CO}_{2}$ 의 phosphoenolpyruvate carboxylase법, urea nitrogen 의 urease with glutamate dehydrogenase (GLDH)법과 uric acid의 uricase법이 있었다(Table 7).

요화학검사항목 중 albumin과 protein은 측정법의 분포 가 일반화학검사와 차이가 있었다. Albumin의 측정법으로는 immunoturbidimetry법이 주로 이용되었고 protein의 측정 법으로 dye binding using pyrogallol red법과 turbidimetry using benzethonium chloride법이 이용되었다(Table 8). 


\section{Journal of LABORATORY MEDICINE and QUALITY ASSURANCE}

\section{Yong-Wha Lee • External Quality Assessment of General Chemistry}

Table 8. Distribution of analytical methods (principle) and coefficients of variation (\%) for the principles of urine chemistry in 2018

\begin{tabular}{|c|c|c|c|c|c|c|c|c|}
\hline \multirow{3}{*}{ Test/method } & \multicolumn{8}{|c|}{ Trials } \\
\hline & \multicolumn{4}{|c|}{1 st } & \multicolumn{4}{|c|}{ 2nd } \\
\hline & $\mathrm{Lab}^{*}$ & $\begin{array}{c}\text { CUC-18- } \\
01\end{array}$ & $\begin{array}{c}\text { CUC-18- } \\
02\end{array}$ & $\begin{array}{c}\text { CUC-18- } \\
03\end{array}$ & $\mathrm{Lab}^{*}$ & $\begin{array}{c}\text { CUC-18- } \\
04\end{array}$ & $\begin{array}{c}\text { CUC-18- } \\
05\end{array}$ & $\begin{array}{c}\text { CUC-18- } \\
06\end{array}$ \\
\hline Albumin & 166 & 30.0 & 19.0 & 19.4 & 172 & 14.2 & 20.3 & 32.5 \\
\hline Dye binding-BCG & 2 & 15.7 & 12.7 & 13.2 & 2 & 33.9 & 26.3 & 44.7 \\
\hline Calcium & 151 & 4.0 & 2.7 & 2.3 & 155 & 4.3 & 2.6 & 3.4 \\
\hline Arsenazo III dye & 19 & 4.1 & 3.0 & 2.7 & 22 & 2.3 & 4.0 & 3.4 \\
\hline Cresolphthalein complexone & 79 & 3.8 & 3.0 & 2.7 & 77 & 3.9 & 2.4 & 3.3 \\
\hline MXB method (methylxylenol blue) & 4 & 2.0 & 1.1 & 1.8 & 5 & 7.3 & 0.9 & 5.4 \\
\hline ISE, undiluted (direct) & 4 & 8.5 & 11.6 & 12.1 & 4 & 15.4 & 15.7 & 15.2 \\
\hline Creatinine & 206 & 5.5 & 4.9 & 4.8 & 209 & 5.2 & 4.9 & 5.1 \\
\hline Compensated kinetic Jaffe method & 50 & 2.0 & 2.7 & 2.5 & 50 & 1.8 & 2.3 & 2.3 \\
\hline Enzymatic method & 10 & 2.4 & 3.1 & 3.5 & 10 & 2.3 & 3.1 & 3.3 \\
\hline kinetic Jaffe method & 56 & 5.1 & 5.2 & 4.5 & 57 & 4.2 & 4.6 & 4.1 \\
\hline Rate blanked compensated kinetic Jaffe method & 89 & 3.7 & 3.7 & 3.4 & 91 & 3.8 & 3.5 & 3.6 \\
\hline Glucose & 135 & 2.2 & 2.2 & 2.2 & 137 & 3.3 & 2.6 & 1.3 \\
\hline Hexokinase & 134 & 2.2 & 2.2 & 2.2 & 136 & 3.3 & 2.7 & 2.6 \\
\hline Magnesium & 109 & 3.0 & 2.8 & 3.5 & 108 & 3.3 & 3.6 & 3.6 \\
\hline Phosphomolybdate, UV & 135 & 2.5 & 2.6 & 2.8 & 135 & 2.6 & 2.8 & 2.9 \\
\hline Potassium & 178 & 2.1 & 3.1 & 3.4 & 184 & 1.8 & 3.6 & 1.9 \\
\hline ISE, diluted (indirect) & 171 & 2.1 & 3.1 & 3.5 & 177 & 1.8 & 3.7 & 1.9 \\
\hline ISE, undiluted (direct) & 4 & 4.2 & 11.9 & 12.5 & 4 & 5.5 & 21.0 & 4.7 \\
\hline Protein & 173 & 11.0 & 9.0 & 8.6 & 177 & 9.9 & 9.0 & 10.5 \\
\hline Biuret method & 5 & 14.3 & 12.1 & 9.3 & 4 & 5.6 & 7.3 & 9.2 \\
\hline dye binding using pyrogallol red & 97 & 13.3 & 10.3 & 9.2 & 102 & 12.5 & 10.0 & 15.0 \\
\hline turbidimetry using benzethonium chloride & 69 & 5.3 & 3.6 & 3.8 & 70 & 5.3 & 3.5 & 5.1 \\
\hline Sodium & 180 & 2.8 & 1.2 & 1.1 & 186 & 2.2 & 1.1 & 2.3 \\
\hline ISE, diluted (indirect) & 172 & 2.8 & 1.2 & 1.0 & 178 & 2.2 & 1.1 & 2.3 \\
\hline ISE, undiluted (direct) & 5 & 3.7 & 3.3 & 4.1 & 5 & 4.3 & 2.6 & 0.0 \\
\hline Urea nitrogen & 152 & 2.9 & 2.8 & 2.3 & 156 & 3.3 & 3.1 & 3.2 \\
\hline Enzymatic UV test (urease-GLDH) & 9 & 5.5 & 1.8 & 3.7 & 9 & 5.4 & 5.7 & 2.8 \\
\hline Urease with GLDH (coupled enzymes) & 143 & 2.8 & 2.5 & 2.3 & 147 & 3.0 & 3.2 & 3.1 \\
\hline
\end{tabular}


Journal of LABORATORY MEDICINE and QUALITY ASSURANCE

Yong-Wha Lee • External Quality Assessment of General Chemistry

Table 8. Continued

\begin{tabular}{|c|c|c|c|c|c|c|c|c|}
\hline \multirow{3}{*}{ Test/method } & \multicolumn{8}{|c|}{ Trials } \\
\hline & \multicolumn{4}{|c|}{$1 \mathrm{st}$} & \multicolumn{4}{|c|}{ 2nd } \\
\hline & $\mathrm{Lab}^{*}$ & $\begin{array}{c}\text { CUC-18- } \\
01\end{array}$ & $\begin{array}{c}\text { CUC-18- } \\
02\end{array}$ & $\begin{array}{c}\text { CUC-18- } \\
03\end{array}$ & $\mathrm{Lab}^{*}$ & $\begin{array}{c}\text { CUC-18- } \\
04\end{array}$ & $\begin{array}{c}\text { CUC-18- } \\
05\end{array}$ & $\begin{array}{c}\text { CUC-18- } \\
06\end{array}$ \\
\hline Uric acid & 145 & 4.3 & 3.5 & 3.6 & 146 & 4.6 & 3.7 & 4.5 \\
\hline Uricase & 143 & 4.4 & 3.5 & 3.6 & 144 & 4.6 & 3.7 & 4.5 \\
\hline
\end{tabular}

Abbreviations: BCG, bromocresol green; NM-BAPTA, 5-nitro-5'-methyl-BAPTA; ISE, ion-selective electrodes; UV, ultra violet; GLDH, glutamate dehydrogenase.

${ }^{*}$ Number of Laboratories participated in Korean External Quality Assessment Service 2018.

2018년 일반화학검사 프로그램과 요화학검사 프로그램의 신빙도조사 결과에 대해 보다 자세한 통계분석 결과는 대한임 상검사정도관리협회 신빙도조사사업 홈페이지(http://eqas. keqas.org)에서 조회가 가능하다.

\section{REFERENCES}

1. Lee YW. Annual report on the external quality assessment scheme for general chemistry in Korea (2017). J Lab Med Qual Assur 2018;40:113-27.
2. Lee YW, Jeon BR, Kim JG, Jun SH, Yun YM, Chun S, et al. Annual report on the external quality assessment scheme for routine clinical chemistry in Korea (2016). J Lab Med Qual Assur 2017;39:61-75.

3. Jun SH, Song J, Song WH; Clinical Chemistry Subcommittee, Korean Association of External Quality Assessment Service. Annual report on the external quality assessment scheme for clinical chemistry in Korea (2015). J Lab Med Qual Assur 2016;38:111-9. 